\title{
Trace level ammonia sensing by SWCNTs (network/film) based resistive sensor using a simple approach in sensor development and design
}

\author{
Prabhash Mishra, Harsh and S S Islam*
}

\begin{abstract}
Highly stable and sensitive detection of trace level (approximately $1 \mathrm{ppm}$ ) of $\mathrm{NH}_{3}$ gas at room temperature is demonstrated for single wall carbon nanotube (SWCNT)-based resistive sensor. The sensor device was comprised of two planer Au electrodes deposited on carbon nanotubes (CNTs) by thermal evaporation method followed by patterning with photolithography process. For the growth of high-quality SWCNTs, multiple catalysts were deposited by co-sputtering method, and the yielded CNTs were in the diameter range of 0.8 to $1.5 \mathrm{~nm}$. The CNTs were characterized by various techniques including Raman spectroscopy, field emission scanning electron microscopy, and transmission electron microscopy. As-grown SWCNTs-based resistive sensor showed an excellent variation in sensor response in the trace sensing range from 1 to $50 \mathrm{ppm}$ of $\mathrm{NH}_{3}$ where the sensor response linearly increased with $\mathrm{NH}_{3}$ concentration. The sensing mechanism was attributed to the electron transfer to the SWCNTs as a result of $\mathrm{NH}_{3}$ oxidation on the nanotube surface. The sensor was found to have good sensitivity with a response time of a few minutes at room temperature. Sensor recovery posed a great problem at room temperature, and the fast and complete recovery was successfully achieved by using appropriate thermal treatment protocol.
\end{abstract}

Keywords: SWCNTs; Spectroscopy; Microscopy; Ammonia sensor

\section{Background}

Carbon nanotubes (CNTs) are one-dimensional (1-D) nanoscale structures based on grapheme sheet and exhibit extraordinary material properties ranging from mechanical to electronic device properties $[1,2]$. As the CNT structure is derived from graphene [3], all of the carbon atoms constitute the entire surface making high surface to volume ratio along with extremely high reactivity of the delocalized electron on surface of the tubular structure, and all these make CNTs more unique for sensing studies. Any change on the surface structure during interaction with reactant molecules leads to a change in their electronic properties, and this enables the detection of the analyte molecules under study.

* Correspondence: safiul5996@gmail.com

Nano-Sensor Research Laboratory, F/O Engineering and Technology, Jamia Millia Islamia (Central University), New Delhi 110025, India
There are large number of reports available in the literature on sensing of chemical gas $[4,5]$ and biological species [6-8] by CNT-based sensors employing various techniques. Both pristine and modified CNTs have been used in these cases where pristine CNTs have shown more intrinsic properties of the CNT materials and demonstrated high sensitivity but failed on selectivity [9]. Modified (or functionalized) CNTs can improve the sensitivity for particular molecules and then provide the selectivity in sensing. There are three aggregate forms of CNTs materials: individual CNTs, network/film made of CNTs, and vertical CNT arrays. Device performances vary astonishingly on the choice of these options. Although individual CNTs are sensitive for chemical detection, the fabrication processes are highly complicated, whereas CNT network/films offer more flexibility in design and development aspect. Not only that the characteristic device properties are independent of types of 
CNTs, i.e., metallic or semiconductor, chirality, and orientation, but at the same time are cost-effective and easy for batch fabrication. The performance of a device made from network/film will show an average effect of all the CNTs used. A variety of sensing mechanisms can be realized in such sensor devices, and in this way, CNT sensor can be used repeatedly [9].

The first SWCNT-based chemical sensor was demonstrated by Kong et al. [5] where $\mathrm{NH}_{3}$ and $\mathrm{NO}_{2}$ detections were recorded for $2 \mathrm{ppm} \mathrm{NO}_{2}$ and $0.1 \%$ of $\mathrm{NH}_{3}$ using field-effect transistor (FET) with little success in sensor recovery. Using the same device structure, Someya et al. [10] found that the recovery time of the FET sensors strongly depended on the voltage biases between the source and the drain. Valentini et al. [11] have demonstrated a resistive SWCNT sensor that could detect sub-ppm $\mathrm{NO}_{2}$ where recovery time is in the order of a few minutes after giving heat to $165^{\circ} \mathrm{C}$ by a backdeposited film heater. SWCNTs covalently attached to poly $(m$-amino benzene sulfonic acid) (SWCNT-PABS) showed improved sensor performance for the detection of $\mathrm{NH}_{3}$ at $5 \mathrm{ppm}$ level [12]. Zhang et al. [13] have pushed the detection limit further to parts per billion level (100 ppb for $\mathrm{NH}_{3}$ and $20 \mathrm{ppb}$ for $\mathrm{NO}_{2}$ ) using similar surface modification (SWCNT-PABS) [14]. Qi et al. showed that non-covalent functionalization by drop casting nafion onto SWCNT-FETs resulted in gas sensors not only with improved sensitivity but also with great selectivity for $\mathrm{NH}_{3}$ [14]. Other demonstrations by Suehiro et al. [15] on $\mathrm{NH}_{3}$ sensing by CNTs gas sensor fabricated by dielectrophoresis (DEP) and solution casting method showed that the sensor response was almost proportional to $\mathrm{NO}_{2}$ concentration. The DEP fabrication could provide a way to trap CNTs on the microelectrode to establish a good electrical connection between CNTs and the external measuring circuit $[16,17]$. Such gas sensor based on CNTs often involves cumbersome processing steps. On the other hand, solution casting is not a reliable method for making a rigid and stable sensing device.

In summary, the $\mathrm{NH}_{3}$ sensing by CNT-based devises is not new, and the sensors have shown extraordinary merits on response, sensitivity, resolution, detection limit, etc. but failed badly when recovery of the device comes into picture. Some success has been achieved in case of devices made with specific expensive design. Literature shows that the major drawback of CNTs-based ammonia detection devices is the slow and incomplete recovery at room temperature due to the tendency of ammonia to strongly interact with carbon nanotubes [18]. It limits their potential commercial application for making an ammonia detection system. To overcome the recovery problem, several research groups are currently trying to achieve fast recovery with ultraviolet (UV) light exposure [19], high gate bias (for FET devices), current pulse (resistive devices) [20], and thermal treatment [21]. All these methods partly improved the recovery of the CNT-based sensors, but are still not satisfactory, in particular, the network/film-based CNT resistive sensors for $\mathrm{NH}_{3}$ detection.

In the present work, the authors report the growth and development of SWCNTs-based resistive sensor for ammonia gas detection at trace level concentration, where SWCNT films were deposited onto $\mathrm{SiO}_{2} / \mathrm{Si}$ by thermal chemical vapor deposition (CVD) technique using cosputtering method for catalyst preparation. Two planer $\mathrm{Au}$ electrodes were deposited onto CNT film by thermal evaporation method followed by pattering with standard lift-off process. A detailed study was carried out for the various sensor parameters such as sensitivity, responserecovery time, and reproducibility for trace level of $\mathrm{NH}_{3}$ concentration. We have been successful in our attempt to detect upto $1 \mathrm{ppm} \mathrm{NH}_{3}$ gas; not only that, the sensors also showed excellent reproducibility with complete and fast recovery by using thermal treatment protocol.

\section{Methods}

The SWCNT film is synthesized by using self-designed thermal CVD method. The schematic diagram of CVD system is shown in Figure 1. The catalyst used to grow SWCNT is obtained by co-sputtering of Fe-Mo metals (thickness of $0.5 \mathrm{~nm}$ ) on $\mathrm{Al}$ metal (thickness of $10 \mathrm{~nm}$ ) used as a supporting layer. The catalyst was annealed at

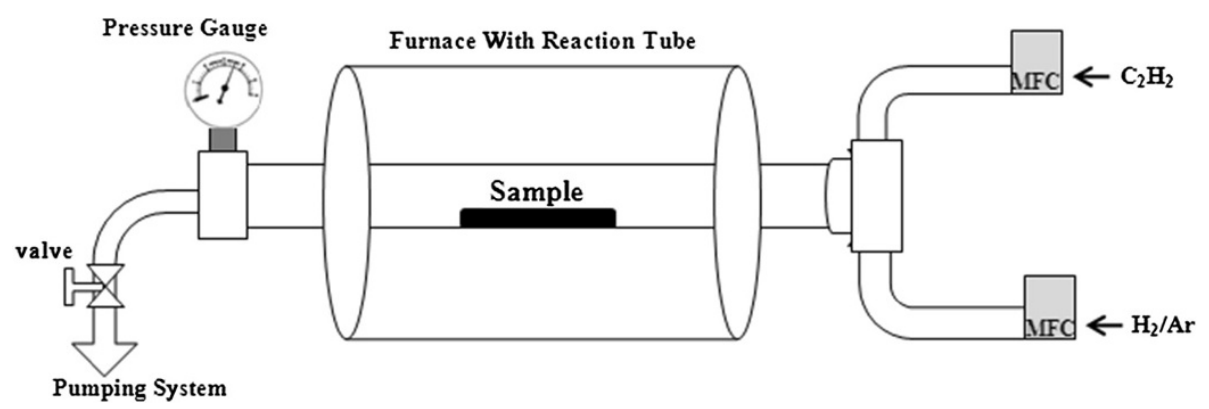

Figure 1 Schematic diagram of CVD system for SWCNTs growth. 


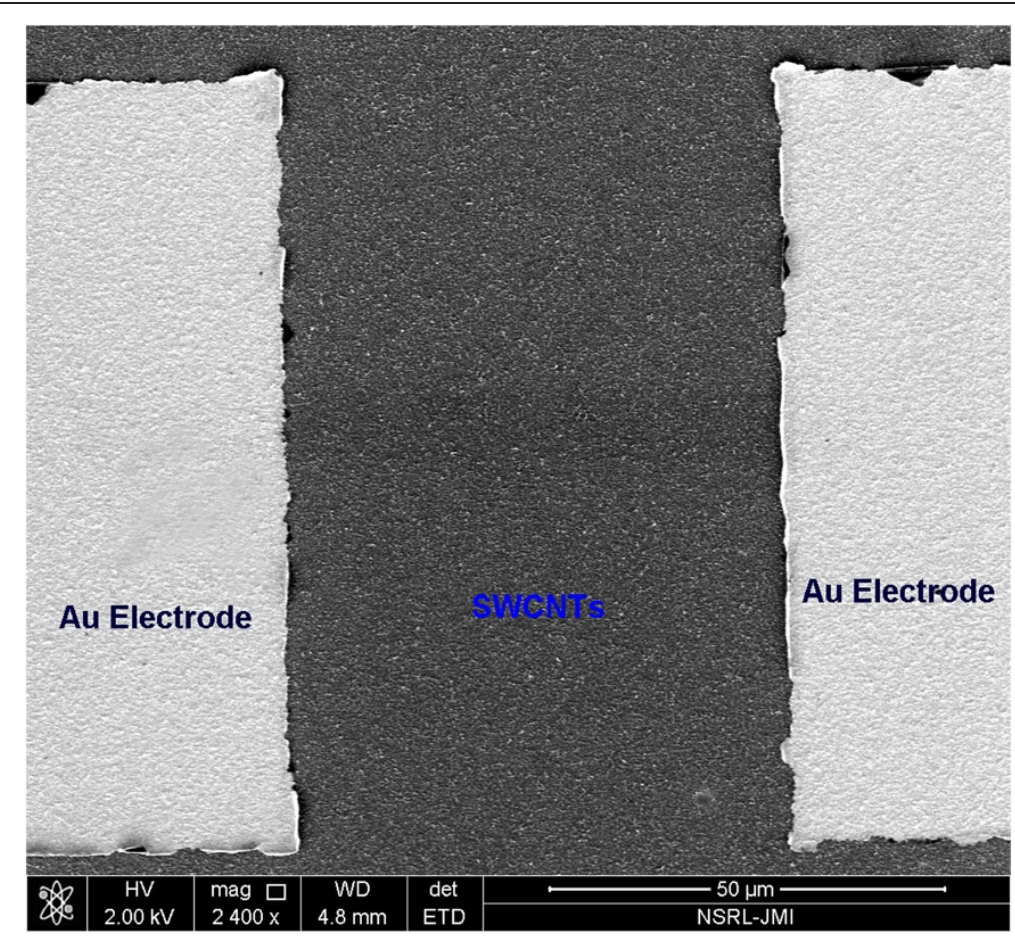

Figure 2 SEM image with design and dimensions of sensor.

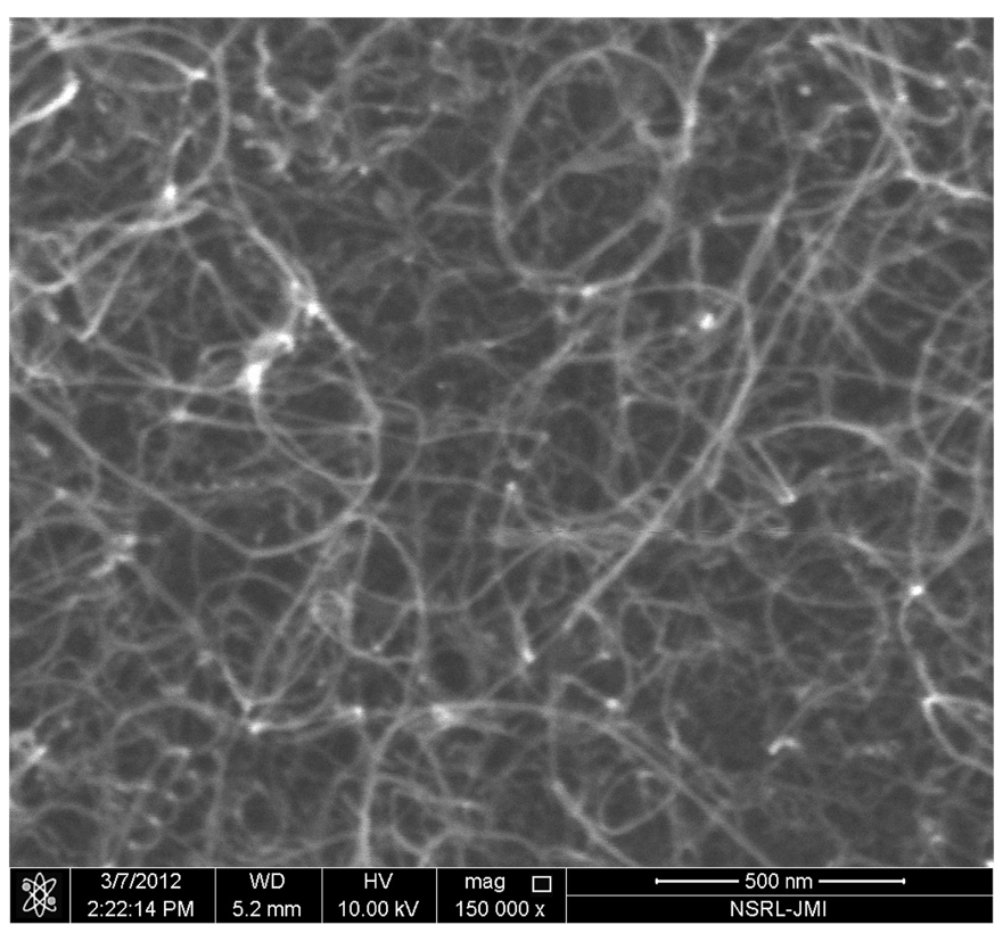

Figure 3 SEM image of as-grown SWCNTs. 


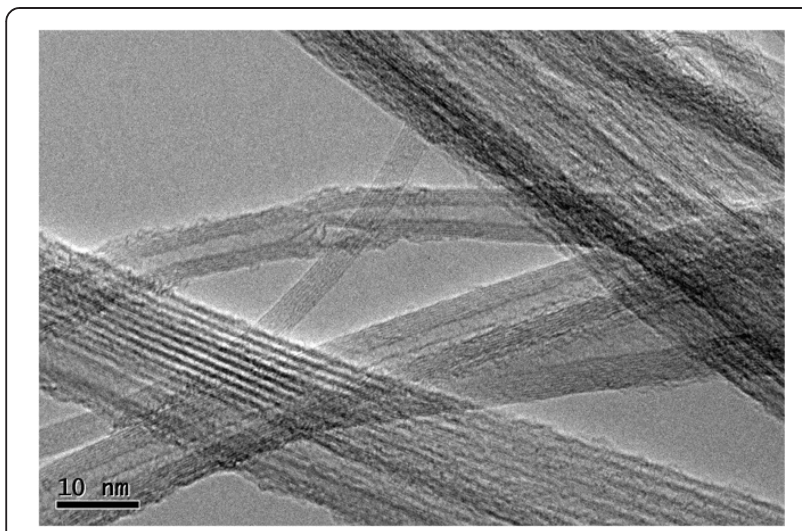

Figure 4 TEM image of SWCNTs grown by thermal CVD.

$900^{\circ} \mathrm{C}$ in $\mathrm{Ar} / \mathrm{H}_{2}$ atmosphere for $30 \mathrm{~min}$. During SWCNTs growth, the flow rate of $\mathrm{H}_{2} / \mathrm{Ar}$ mixture and acetylene $\left(\mathrm{C}_{2} \mathrm{H}_{2}\right)$ in chamber was kept at 30 and $5 \mathrm{sccm}$ respectively to continue the growth for $5 \mathrm{~min}$. The growth pressure is carefully controlled at 50 Torr.

Surface morphology was examined by high-resolution field emission scanning electron microscopy (FESEM) (Nova Nano Sem450, FEI) and transmission electron microscope (TEM, FEI Tecnai F20) was used at an accelerated voltage of $200 \mathrm{kV}$. Carbon defects including catalytic impurities and structure orientation were analyzed using lab RAM HR 800 (Horiba JY; Horiba) micro-Raman spectrometer at $632.8 \mathrm{~nm}$. The laser beam was focused on the sample using confocal microscope with LWD $\times 50$ objective of N.A. $=0.7$.

Sensor was fabricated in chemiresistive mode by making two planer Au electrodes on network-like SWCNT film by lift-off process. The electrical measurements were done using electrical characterization unit (Keithley 4200 SCS). Concentration and flow rate of ammonia were set and maintained by using gas mixing system (Environics, USA).

\section{Results and discussion}

\section{Sensor design and development details}

The sensing area comprising SWCNTs was grown by thermal CVD system on $\mathrm{SiO}_{2} / \mathrm{Si}$ substrate, and the electrode made of gold pattern structure with $60-\mu \mathrm{m}$ channel length was fabricated by standard photolithography technique. The design and dimensions of the sensor are given in Figure 2.

\section{Sensor characterization SEM and TEM studies}

The surface morphology, dimension, and orientation of SWCNTs can be characterized by scanning electron microscope has been employed to study the morphology of SWCNTs. The samples were directly mounted on a standard aluminum fixture using double-sided carbon tape. High-resolution images of SWCNTs were taken at accelerating voltages ranging from 2 to $10 \mathrm{kVA}$ and the working distance between 4 and $6 \mathrm{~mm}$. High-resolution FESEM image (Figure 3) of SWCNTs shows a film having network-like patterns and successive growth of SWCNTs. The image at higher magnification shows that the growth of SWCNT film had taken place in a network fashion having random orientation of the tube with uniform dimensions.

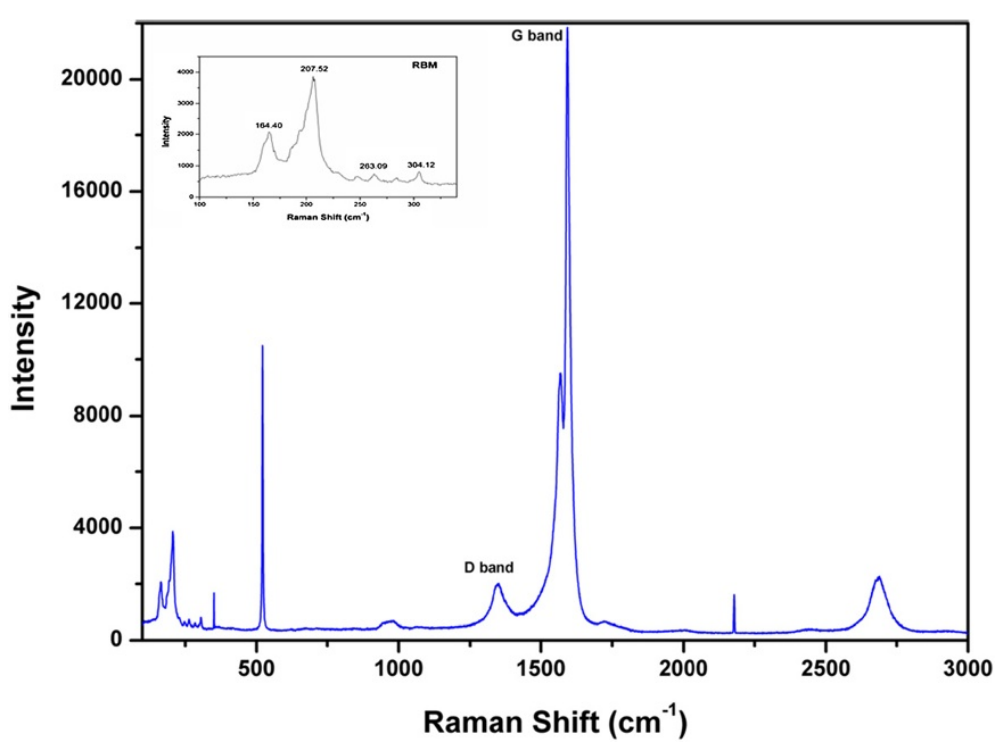

Figure 5 Raman spectra of SWCNTs and magnified RBM peak (insert). 
Table 1 Radial breathing (RBM) peak analysis

\begin{tabular}{cc}
\hline $\boldsymbol{\omega}_{\text {rbm }}\left(\mathbf{c m}^{-\mathbf{1}}\right)$ & Diameter $(\mathbf{n m})$ \\
\hline 164.40 & 1.50 \\
207.52 & 1.19 \\
263.09 & 0.94 \\
304.12 & 0.82 \\
\hline
\end{tabular}

Transmission electron microscope (TEM) was used at an accelerated voltage of $200 \mathrm{kV}$. HRTEM image (Figure 4) shows SWCNT produced by the co-sputtering of Mo-Fe on supporting Al layer pre-coated on $\mathrm{SiO} 2 / \mathrm{Si}$ substrate. In the HRTEM image, the SWCNTs shown are in bundle form. The average tube diameter estimated by TEM analysis using digital micrograph program (d-spacing values) software was found to be nearly $1.43 \mathrm{~nm}$.

\section{Raman studies}

Carbon defects including catalytic impurities and structure orientation were analyzed using micro-Raman spectrometer at $632.8 \mathrm{~nm}$. The laser beam was focused on the sample using a confocal microscope. The Raman spectra of synthesized SWCNT are shown in Figure 5. The spectra indicate sharp peak of first-order tangential $G$ band and defect-related second-order $D$ band at $1,592 \mathrm{~cm}^{-1}$ and $1,347 \mathrm{~cm}^{-1}$, respectively. In SWCNTs, tangential G-band mode gives rise to multi-peak feature due to the symmetry breaking. The G-band feature can also be used to characterize the metal or semiconducting characters of SWCNTs, although the Raman line shape for metallic SWCNTs is not distinctly observed in comparison with the narrow symmetrical line shape for semiconducting SWCNTs [22].
$\mathrm{D}$ band is activated in second-order scattering process of $s p^{2}$ carbon due to vacancy, grain boundary, and tube defects. The estimated ratio of $I_{\mathrm{d}} / I_{\mathrm{g}}$ from Figure 5 was 0.09 . The low $I_{\mathrm{d}} / I_{\mathrm{g}}$ ratio indicates that the SWCNTs have perfect graphite structures. The radial breathing mode (RBM) peak of Raman spectra (Table 1) was used to study the SWCNT diameter. The diameters of SWCNTs were obtained in the range from 0.8 to $1.5 \mathrm{~nm}$ which are calculated by frequency of RBM peak from the Equation $1[22]$ as

$$
\omega_{\mathrm{rbm}}=\frac{A}{d_{\mathrm{t}}}+B
$$

\section{Ammonia detection procedure}

The sensing element was placed in a small and sealed sensing chamber made up of steel with heater arrangement inside (Linkam, Scientific Instruments Ltd., Tadworth, Surrey, UK). Nitrogen gas (which acted as a carrier gas) was made to flow into the chamber continuously before the test gas (ammonia) was introduced. The concentration of ammonia was controlled by using software-operated gas mixing system. The resistance of the CNTs film was recorded when the system reached to a steady state. The sample was tested for its electrical response by measuring the change in resistance across its two terminals when exposed to different concentrations (ppm) of ammonia. The schematic diagram of ammonia detection setup used to take ammonia gas sensing measurements is shown in Figure 6.

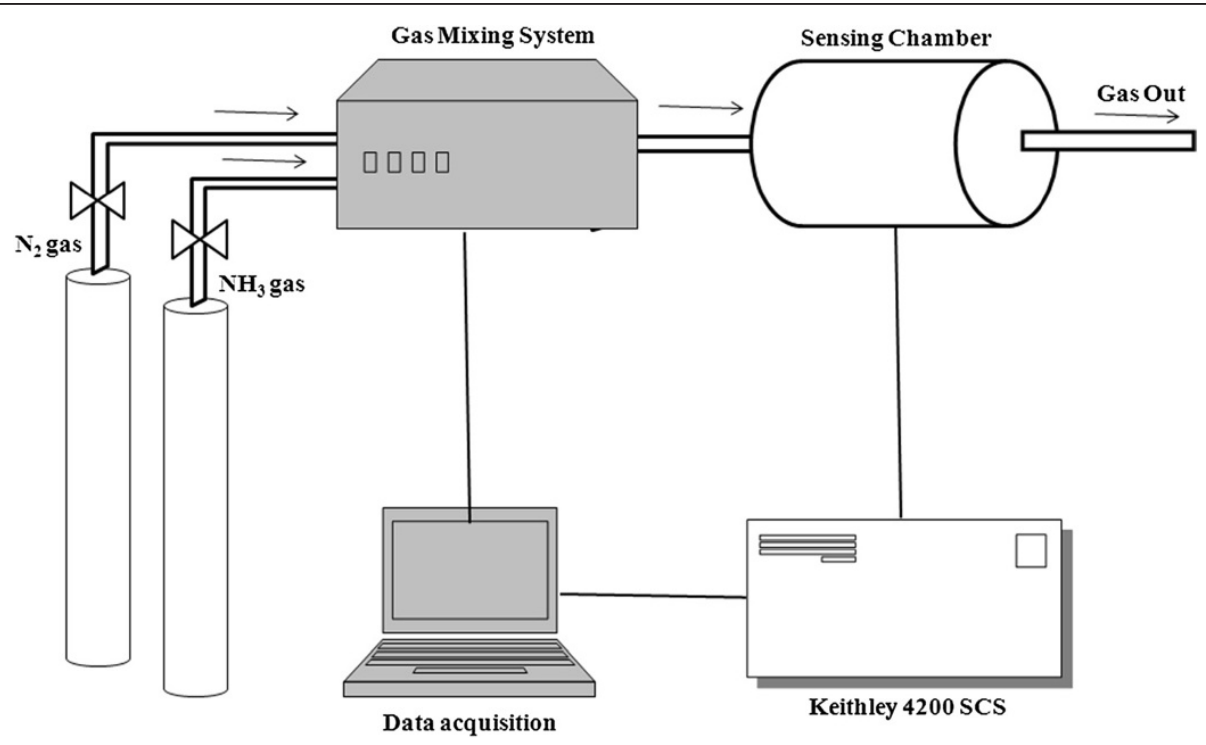

Figure 6 Schematic diagram of the setup for ammonia gas sensing. 


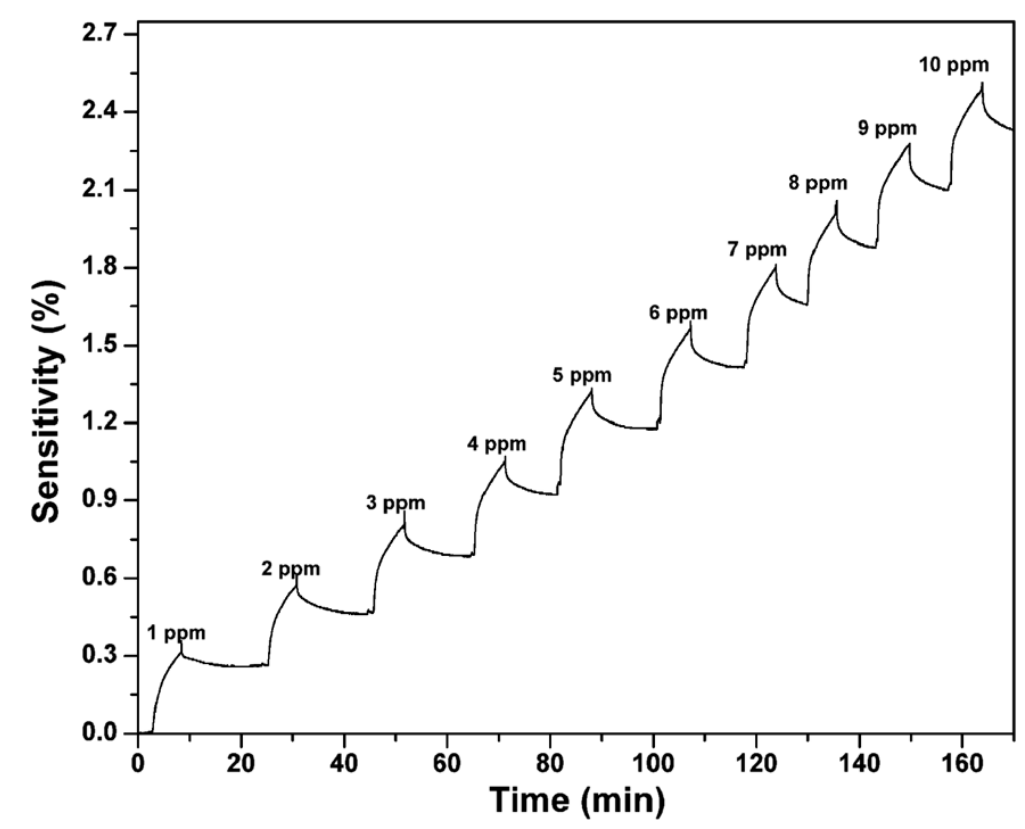

Figure 7 Dynamic response and recovery characteristics of SWCNTs-based sensor to 'ammonia' molecules.

\section{Sensing response}

In our sensor, SWCNTs were aligned between the two $60-\mu \mathrm{m}$ microfabricated gold electrodes to examine the $\mathrm{NH} 3$ gas detection at trace level. The dynamic response and recovery characteristics of the sensor are given in Figure 7. The normalized response of sensor is defined as $\left(R-R_{\mathrm{o}} / R_{\mathrm{o}}\right)$ where $R_{\mathrm{o}}$ is initial resistance of the sensor before exposure to $\mathrm{NH}_{3}$ gas and $R$ is the maximum resistance after $\mathrm{NH}_{3}$ exposure as determined as a function of $\mathrm{NH}_{3}$ gas concentration. The gas sensor response was tested as a function of $\mathrm{NH}_{3}$ gas range of 1 to 10 ppm (in Figure 7). From theoretical and experimental studies, we conclude that the change in electrical response occurred due to the changes in electronic properties of SWCNT on exposure to $\mathrm{NH}_{3}$ due to charge transfer from $\mathrm{NH}_{3}$ gas (electrons donor) to carbon

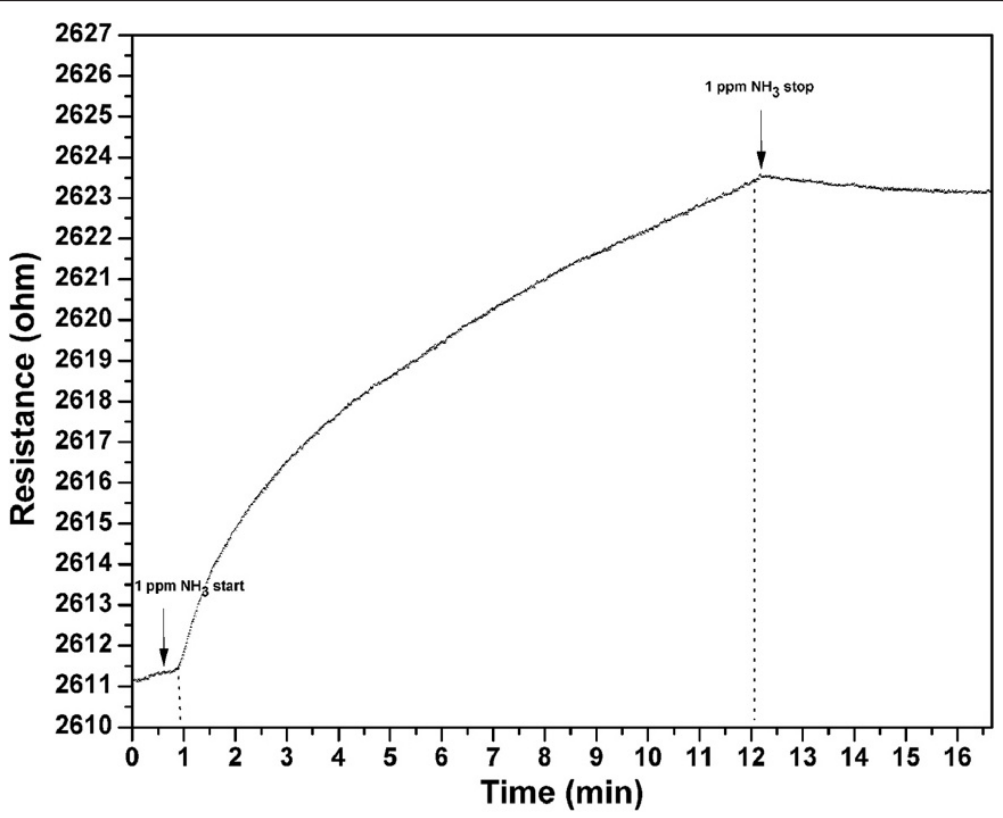

Figure 8 Response-recovery of SWCNTs-based resistive sensor to 1 ppm $\mathrm{NH}_{3}$ at room temperature. 


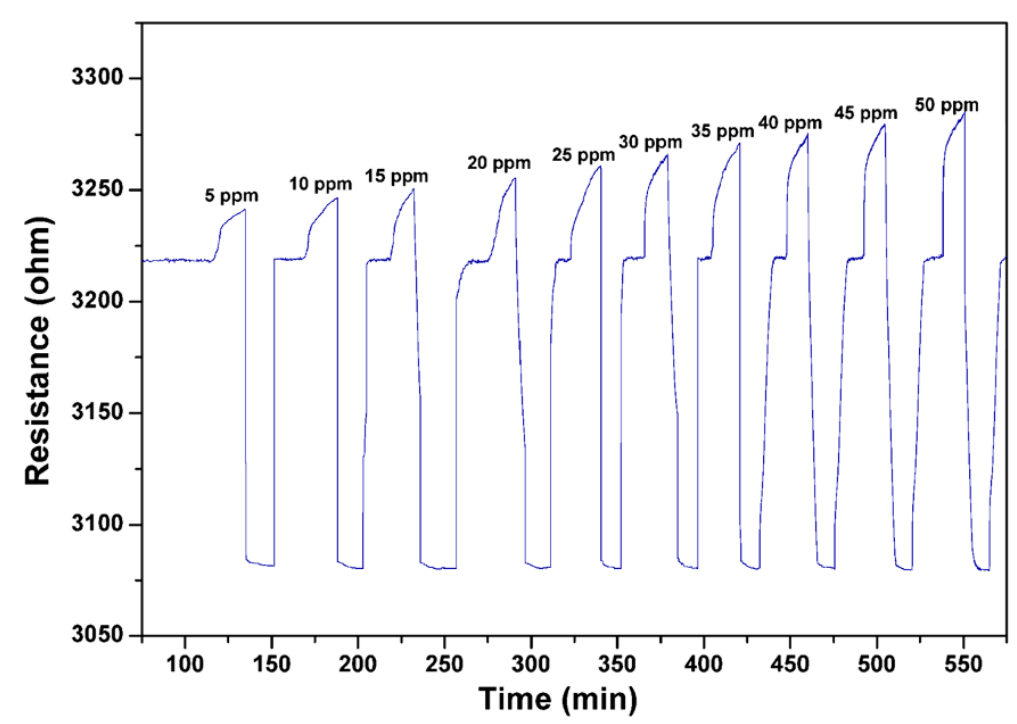

Figure 9 Response of SWCNTs-based resistive sensor to ammonia molecules.

nanotube surface by means $\pi-\pi$ stacking and change its density of state [23].

We have observed that the sensor does not show complete recovery of its initial resistance. The sensor recovered only $60 \%$ to $70 \%$ after stop of $\mathrm{NH}_{3}$ gas flow. The literature survey of CNT shows recovery over a long duration of time, i.e., more than $12 \mathrm{~h}$ [24]. It is well known that the adsorption process of $\mathrm{NH}_{3}$ gas on CNTs is attributed to both physisorption and chemisorptions. Chemisorptions may take place due to site defect on the sidewall of CNTs $[25,26]$. It is reported that the binding energy of chemisorbed ammonia is quite high [26] and to desorb that from CNTs surface, we need to apply some external excitation energy to the system. To improve the recovery time, current stimulation, illumination of UV light, and heat treatment have been used as external source of energy [27]. Figure 8 shows the sensor response of the chemiresistive sensor where negligible recovery at room temperature is observed even after spending $12 \mathrm{~h}$ using continuously dry $\mathrm{N}_{2}$ flow. Thermal treatment process was employed in this work to acquire fast and complete recovery.

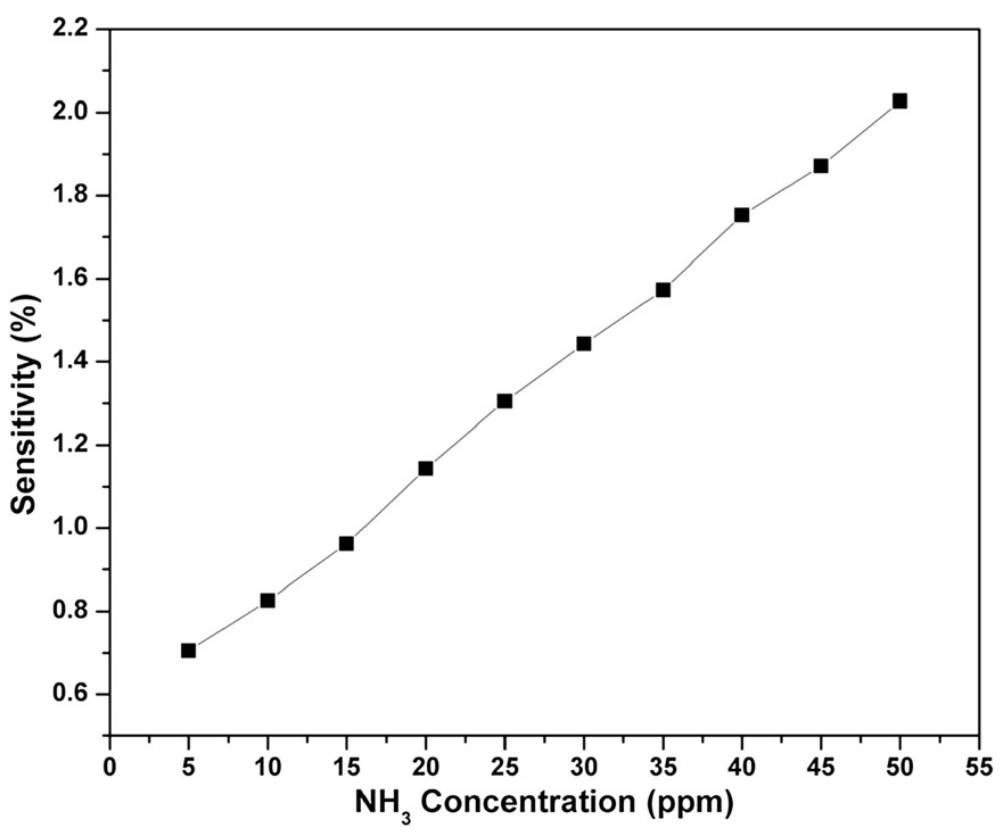

Figure 10 Sensitivity plot of sensor for 5 to 50 ppm of ammonia gas. 
In order to have fast and complete recovery, a heating procedure for a fixed duration (10 $\mathrm{min}$ ) and subsequent cooling to room temperature was followed in a step sequence controlled by a temperature controller. The temperature-dependent recovery was studied in the temperature range from $27^{\circ} \mathrm{C}$ to $200^{\circ} \mathrm{C}$. The optimized heating temperature was set at $200^{\circ} \mathrm{C}$ for the sensor recovery, i.e., to bring back the sensing element to its initial resistance. Recovery of sensor after desorption of $\mathrm{NH}_{3}$ gas is shown in Figure 9; the response and recovery curve of sensor is shown for successive exposure of various concentration of $\mathrm{NH}_{3}$ (5 to $50 \mathrm{ppm}$ ). Figure 10 shows the sensitivity of the sensor that is linearly increased for different concentrations of ammonia, which was found to be proportional to the gas concentration at room temperature.

Although the observed sensitivity of the sample is not found as good as expected, the overall performance of the system with respect to other sensing parameters (i.e., reproducibility, response, and recovery time) is found to be satisfactory. Our research group is currently working on the issue related to the improvement of sensitivity by using various methods.

\section{Conclusions}

We have designed a chemiresistive SWCNT-based sensor by thermal CVD for the detection of low concentration of NH3 gas. The sensor was thoroughly examined using FESEM, TEM, and Raman techniques which confirm the presence of SWCNTs randomly oriented on $\mathrm{SiO}_{2} / \mathrm{Si}$ film after electrode patterning, thereby facilitating the required interaction of sensor with gas molecules in order to make this material suitable for utilizing as gas detection system. An ammonia detector was successfully realized that could detect low concentration (ppm) of ammonia with repeatable results. Thermal treatment method was employed to achieve complete and fast recovery with proper selection of thermal treatment regime. Although the observed sensitivity of the sample is not found as good as expected, the overall performance of the sensor with respect to other sensing parameters (i.e., reproducibility, response, and recovery time) is found to be satisfactory. Hence, this study has opened up possibilities for further improvement of the quality of the sensor so that detection level may be lowered to sub-ppm level.

\section{Competing interests}

The authors declare that they have no competing interests.

\section{Authors' contributions}

PM carried out the experimental work. $\mathrm{H}$ guided in writing work of the paper. SSI provided guidance for carrying out experiment work, analyzing the experimental data and writing of the paper. All authors have read and approved the manuscript.

\section{Authors' information}

Prabhash Mishra has received his Masters degree in Electronics from F/O Engineering and Technology at Jamia Millia Islamia (Central University), New Delhi, India in 2009, and he is currently working towards Ph.D. in electronic science. His research is focused on fabrication and characterization of gas sensing devices using CNT, ceramics and silicon. Harsh has received his Ph. D. degree in Physics from Jamia Millia Islamia University. He is a retired scientist from Solid State Physics Laboratory (sspl), Defence R\&D Organization (DRDO), Ministry of Defence, India. His research interests include fabrication and development of devices. S. S. Islam is a professor of Material Sciences \& Electronic Devices, F/O Engineering and Technology at Jamia Millia Islamia (Central University). He has obtained Ph.D. degree in Material Sciences in 1989 from University of Paris (6), France. He has contributed several papers to international journals and also leads the Nano-Sensor Reasearch Laboratory at Jamia Millia Islamia(Central University) guiding many Ph.D. students. His research interests widely include solid state lithium batteries, III-V nanostructured materials, high speed nano devices, electrical and optical sensors fabricated using porous silicon, ceramics and CNT.

Received: 8 February 2013 Accepted: 22 June 2013

Published: 19 Jul 2013

\section{References}

1. lijima, $\mathrm{S}$, Ichihashi, $\mathrm{T}$ : Single shell carbon nanotubes of 1-nm diameter. Nature 363, 603 (1993)

2. Li, J, Ng, HT: Carbon nanotube sensors. In: Nalwa, HS (ed.) Encyclopedia of Nanoscience and Nanotechnology, vol. 1, pp. 591-601. ASP, USA (2004)

3. Ijima, S: Helical microtubules of graphitic carbon. Nature 354, 56 (1991)

4. Rajaputra, S, Mangu, R, Clore, P, Qian, D, Andrews, R, Singh, VP: Multi-walled carbon nanotube arrays for gas sensing applications. Nanotechnology 19, 345502 (2008)

5. Kong, J, Franklin, N, Zhou, C, Chapline, M, Peng, S, Cho, K, Dai, H: Nanotube molecular wires as chemical sensors. Science 287, 622 (2000)

6. Cella, LN, Sanchez, P, Zhong, W, Myung, NV, Chen, W, Mulchandani, A: Nano aptasensor for protective antigen toxin of anthrax. Anal. Chem. 82, 2042 (2010)

7. Jeseung, O, Yo, S, Young, WC, Kookjin, L, Yo, KH: Carbon nanotube-based biosensor for detection hepatitis B. Curr. Appl. Phys. 9, E229 (2009)

8. So, HM, Park, DW, Jeon, EK, Kim, YH, Kim, BS, Lee, CK, Choi, SY, Kim, SC, Chang, H, Lee, JO: Detection and titer estimation of Escherichia coli using aptamer-functionalized single-walled carbon-nanotube field-effect transistors. Small 4, 197 (2008)

9. Lim, TC: Theory and Applications in Industry, Healthcare and Defense. CRC Press by Taylor and Francis group, Boca Raton, FL (2011)

10. Someya, T, Small, J, Kim, P, Nuckolls, C, Yardley, JT: Alcohol vapor sensors based on single-walled carbon nanotube field effect transistors. Nano. Lett. 3, 877 (2003)

11. Valentini, L, Armentano, I, Kenny, JM, Cantalini, C, Lozzi, L, Santucci, S: Sensors for sub-ppm NO2 gas detection based on carbon nanotube thin films. Appl. Phys. Lett. 82, 961 (2003)

12. Bekyarova, E, Davis, M, Burch, T, Itkis, ME, Zhao, B, Sunshine, S, Haddon, RC: Chemically functionalized single-walled carbon nanotubes as ammonia sensors. J. Phys. Chern. B. 108, 19717 (2004)

13. Zhang, T, Mubeen, S, Bekyarova, E, Yoo, BY, Haddon, RC, Myung, NY, Deshusses, MA: Poly ( $m$-amino benzene sulfonic acid) functionalized single-walled carbon nanotubes based gas sensor. Nanotechnology 18, 165504 (2007)

14. Qi, P, Vermesh, O, Grecu, M, Javey, A, Wang, Q, Dai, H: Toward large arrays of multiplex functionalized carbon nanotube sensors for highly sensitive and selective molecular detection. Nano. Lett. 3, 347 (2003)

15. Junya, S, Guangbin, Z, Masanori, H: Fabrication of a carbon nanotube-based gas sensor using dielectrophoresis and its application for ammonia detection by impedance spectroscopy. J. Phys. D: Appl. Phys. 36, L109 (2003)

16. Philip, B, Abraham, J, Chandrasekhar, A, Varadan, VK: Carbon nanotube/PMMA composite thin films for gas-sensing applications. Smart. Mater. Struct. 12, 935 (2003)

17. Suehiro, J, Zhou, G, Hara, M: Detection of partial discharge in SF6 gas using a carbon nanotube-based gas sensor. Sens. Actuators. B. 105, 164 (2005)

18. Kauffman, DR, Star, A: Carbon nanotube gas and vapor sensors. Angew. Chem. Int. Ed. 47, 6550 (2008)

19. Zhang, T, Mubeen, S, Myung, NV, Deshusses, MA: Recent progress in carbon nanotube-based gas sensors. Nanotechnology 19, 332001 (2008)

20. Salehi-Khojin, A, Lin, KY, Field, CR, Masel, RI: Non-thermal current stimulated desorption of gases from carbon nanotubes. Science 329, 1327 (2010) 
21. Nguyen, H, Huh, JS: Behavior of single-walled carbon nanotube-based gas sensors at various temperatures of treatment and operation. Sensors and Actuators B. 117, 426 (2006)

22. Dresselhaus, MS, Dresselhaus, G, Jorio, A, Souza Filho, AG, Saito, R: Raman spectroscopy on isolated single wall carbon nanotubes. Carbon 40, 2043 (2002)

23. Kostyrko, T, Bartkowiak, M, Mahan, G: Reflection by defects in a tightbinding model of nanotubes. Phys. Rev. B. 59, 3241 (1999)

24. Li, J, Lu, Y, Ye, Q, Cinke, M, Han, J, Meyyappan, M: Epitaxial directional growth of indium-doped tin oxide nanowire arrays. Nano. Lett. 3, 929 (2003)

25. Robinson, JA, Snow, ES, Badescu, SC, Reinecke, TL, Perkins, FK: Role of defects in single-walled carbon nanotube chemical sensors. Nano. Lett. 6, 1747 (2006)

26. Feng, $X$, Irle, $S$, Witek, $H$, Morokuma, $K$, Vidic, $R$, Borguet, E: Sensitivity of ammonia interaction with single-walled carbon nanotube bundles to the presence of defect sites and functionalities. J. Am. Chem. Soc. 127, 10533 (2005)

27. Salehi-Khojin, A, Khalili-Araghi, F, Kuroda, MA, Lin, KY, Leburton, JP, Masel, Rl: On the sensing mechanism in carbon nanotube chemiresistors. ACS. Nano. 5, $153(2011)$

10.1186/2228-5326-3-46

Cite this article as: Mishra et al:: Trace level ammonia sensing by

SWCNTs (network/film) based resistive sensor using a simple approach in sensor development and design. International Nano Letters 2013, 3:46

\section{Submit your manuscript to a SpringerOpen ${ }^{\circ}$ journal and benefit from:}

- Convenient online submission

- Rigorous peer review

- Immediate publication on acceptance

- Open access: articles freely available online

- High visibility within the field

- Retaining the copyright to your article 